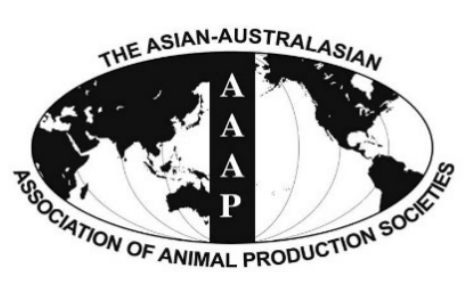

Open Access

Asian Australas. J. Anim. Sci.

Vol. 29, No. 5 : 695-701 May 2016

http://dx.doi.org/10.5713/ajas.15.0256

www.ajas.info

pISSN 1011-2367 elSSN 1976-5517

\title{
Antioxidant Enzyme Activity, Iron Content and Lipid Oxidation of Raw and Cooked Meat of Korean Native Chickens and Other Poultry
}

\author{
Muhlisinn, ${ }^{1, a}$, Dicky Tri Utama a, Jae Ho Lee, Ji Hye Choi, and Sung Ki Lee* \\ Animal Products and Food Science Program, Division of Animal Applied Science, College of Animal Life Sciences, \\ Kangwon National University, Chuncheon 24341, Korea
}

\begin{abstract}
This study was conducted to observe antioxidant enzyme activity, iron content and lipid oxidation of Korean native chickens and other poultry. The breast and thigh meat of three Korean native chicken breeds including Woorimatdak, Hyunin black and Yeonsan ogye, and three commercial poultry breeds including the broiler, White Leghorn and Pekin duck (Anasplatyrhyncos domesticus) were studied. The analyses of the antioxidant enzymes activity, iron content and lipid oxidation were performed in raw and cooked samples. The activity of catalase (CAT) in the thigh meat was higher than that of the breast meat of three Korean native chickens and the broiler, respectively. The activity of glutathione peroxidase (GPx) in the uncooked thigh meat of three Korean native chickens was higher than that of the breasts. The breast meat of Woorimatdak and Pekin duck had higher superoxide dismutase (SOD) activity than the others, while only the thigh meat of Pekin duck had the highest activity. Cooking inactivated CAT and decreased the activity of GPx and SOD. The thigh meat of Woorimatdak, White Leghorn, Yeonsan ogye and Hyunin black contained more total iron than the breast meat of those breeds. The heme-iron lost during cooking ranged from 3.2\% to $14.8 \%$. It is noted that the thigh meat had higher thiobarbituric acid reactive substances values than the breast in all chicken breeds. Though Woorimatdak showed higher antioxidant enzyme activity and lower released-iron percentage among Korean native chickens, no differences were found on lipid oxidation. We confirm that the dark meat of poultry exhibited higher antioxidant enzyme activity and contained more iron than the white meat. (Key Words: Antioxidant Enzyme Activity, Iron Content, Korean Native Chicken, Lipid Oxidation)
\end{abstract}

\section{INTRODUCTION}

Lipid oxidation is one of the major factors affecting meat quality. It promotes off-odor and off-flavor formation, color changes and quality deterioration of meat. Lipid oxidation causes the loss of nutritional and functional value and generates compounds that have negative effects on human health. Furthermore, lipid oxidation can diminish the sensory properties that are the main factors in consumer meat purchasing (Min and Ahn, 2005; McMillin, 2008).

Lipid oxidation occurs in meat through three general stages of free radical chain reaction: Initiation, propagation,

\footnotetext{
* Corresponding Author: Sung Ki Lee. Tel: +82-33-250-8646, Fax:

+82-33-259-5574, E-mail: skilee@kangwon.ac.kr

${ }^{1}$ Faculty of Animal Science, Universitas Gadjah Mada, Yogyakarta 55281, Indonesia.

${ }^{a}$ These two authors contributed equally to this study.

Submitted Mar. 23, 2015; Revised May 18, 2015; Accepted Nov. 10, 2015
}

and termination. During these processes, aside from the main external factor (i.e., oxygen), meat endogenous free radicals and transition metals are believed to play a critical role as initiators, catalysts and intermediates in lipid oxidation (Halliwell and Gutteridge, 1990). Iron is the most probable catalyst for the initiation of lipid peroxidation by catalyzing the generation of most hydroxyl radicals $(\cdot \mathrm{OH})$ (Buettner and Jurkiewicz, 1996). About two-thirds of iron in the body is found in hemoglobin, with smaller amounts found in myoglobin, iron-containing enzymes and transferrin. However, not all iron contained in meat promotes lipid oxidation. Min and Ahn (2005) noted that free ionic iron released from heme pigments and ferritin may be considered as the major catalysts in lipid oxidation. The concentrations of hemoglobin and myoglobin in meat tissues are dependent on the animal species, meat type and anatomical location of meat (Schricker et al., 1982). Because the majority of iron is bound in myoglobin and the amount of myoglobin in meat 
may vary depending on the species and muscles, a study measuring the iron contained in various meat parts from different species is important.

Organisms have developed enzymatic defense systems that defend against lipid oxidation. Enzymatic defense mechanisms in meat occur through the activity of antioxidant enzymes including catalase (CAT), glutathione peroxidase (GPx) and superoxide dismutase (SOD) (Min et al., 2008). CAT and GPx are considered the major peroxide-removing enzymes located in cytosol, while SOD plays role in the protection against damage resulting from superoxide anion radicals (Chan and Decker, 1994). SOD and CAT are coupled enzymes, in which SOD scavenges superoxide anions by forming hydrogen peroxide, and CAT safely decomposes hydrogen peroxide to water and superoxide anions; GPx can decompose both hydrogen peroxide and lipoperoxides formed during lipid oxidation (Gatellier et al., 2004; Terevinto et al., 2010).

Antioxidant enzyme activities differ among the meat of different species (Pradhan et al., 2000; Chen et al., 2012) and meat types (Hernandez et al., 2004). Hernandez et al. (2004) noted that antioxidant enzyme activity also varied among animals of a single species as well as different genetic types. Although previous studies have reported enzyme activity and iron content of different species and meat parts, additional studies of species of native animals from specific locations may add new information in this research field. The objective of this study was to observe antioxidant enzyme activity, iron content and lipid oxidation in raw and cooked meat of Korean native chickens and other poultry.

\section{MATERIALS AND METHODS}

\section{Sample preparation}

Three Korean native chicken breeds including the Woorimatdak, Yeonsan ogye, and Hyunin black aged 12 weeks and three commercial poultry breeds including the broiler aged 5 weeks, White Leghorn aged 12 weeks and Pekin duck (Anasplatyrhyncos domesticus) aged 7 weeks were used in this study. Breast and thigh meat of the broiler, Woorimatdak and Pekin duck were purchased from a local market (Chuncheon, Kangwon province, Korea). The White Leghorn, Yeonsan ogye and Hyunin black were raised at a chicken farm at Seoul National University (Suwon, Korea) and were slaughtered manually. After slaughtering, the breast and thigh meat were obtained. Samples were packed aerobically in an oxygen-permeable resealable bag (polyethylene, $25 \times 30 \mathrm{~cm}$; Clean-wrap, Gimhe, Korea). The samples were kept chilled in an icebox and were transported to the laboratory of meat science, Kangwon National University. Samples were then stored at chilling room $\left(2^{\circ} \mathrm{C} \pm 1^{\circ} \mathrm{C}\right)$ overnight and were analyzed the day after. For the cooking studies, the samples were transferred to smaller oxygen-permeable resealable bags (polyethylene, $12.5 \times 15$ $\mathrm{cm}$; Cleanwrap, Korea) and cooked in a $95^{\circ} \mathrm{C}$ water bath to an internal temperature of $75^{\circ} \mathrm{C}$ followed by cooling at $5^{\circ} \mathrm{C}$ for $4 \mathrm{~h}$. The raw and cooked samples were chopped and immediately analyzed.

\section{Antioxidant enzymes activity measurement}

Catalase: CAT activity was measured by measuring the disappearance of $\mathrm{H}_{2} \mathrm{O}_{2}$ characterized by a decrease in absorbance at $240 \mathrm{~nm}$ according to a modififed version of a method described by Aebi (1984). A $5 \mathrm{~g}$ sample was mixed with $25 \mathrm{~mL}$ of $50 \mathrm{mM}$ phosphate buffer $\left(\mathrm{pH} 7.0\right.$ at $\left.25^{\circ} \mathrm{C}\right)$ using a homogenizer (Ultra-Turrax T25 basic, IkaWerke $\mathrm{GmbH} \&$ Co., Staufen, Germany) for $15 \mathrm{~s}$ at 13,500 rpm. The mixture was centrifuged at $1,800 \times g$ at $2^{\circ} \mathrm{C}$ for $15 \mathrm{~min}$. The supernatant of the mixture was taken and filtered through a Whatman filter paper No. 1. Then, $100 \mu \mathrm{L}$ of filtered supernatant was mixed with $2.9 \mathrm{~mL}$ of $30 \mathrm{mM} \mathrm{H}_{2} \mathrm{O}_{2}$. The decrease in absorbance at $240 \mathrm{~nm}$ was recorded every $30 \mathrm{~s}$ for $3 \mathrm{~min}$. The CAT activity was expressed as units/g sample.

Glutathione peroxidase: The GPx activity measurement was performed by homogenizing $5 \mathrm{~g}$ of a sample with $25 \mathrm{~mL}$ of $50 \mathrm{mM}$ phosphate buffer $\left(\mathrm{pH} 7.0\right.$ at $\left.25^{\circ} \mathrm{C}\right)$ using a homogenizer at $13,500 \mathrm{rpm}$ for $30 \mathrm{~s}$. The mixture was centrifuged at $1,800 \times g$ for $15 \mathrm{~min}$ at $2^{\circ} \mathrm{C}$ then filtered through a Whatman filter paper No 1. A volume of $100 \mu \mathrm{L}$ of the supernatant was mixed with the following: $0.5 \mathrm{~mL}$ of phosphate buffer- $0.001 \mathrm{M}$ ethylenediaminetetraacetic acid$0.1 \mathrm{M} \mathrm{NaN}_{3}, 100 \mu \mathrm{L}$ of the assay mixture containing 5 units $/ \mathrm{mL}$ glutathione reductase (Sigma G3664, SigmaAldrich, St. Louis, MO, USA) in phosphate buffer, $100 \mu \mathrm{L}$ of $10 \mathrm{mM}$ glutathione (Sigma G4251, Sigma-Aldrich, USA), $100 \mu \mathrm{L}$ of $1.5 \mathrm{mM}$ nicotinamide adenine dinucleotide phosphate (Sigma N1630, Sigma-Aldrich, USA), and $100 \mu \mathrm{L}$ of $1.5 \mathrm{mM} \mathrm{H}_{2} \mathrm{O}_{2}$ (Sigma H1009, Sigma-Aldrich, USA). The GPx activity was measured by recording the decrease in absorbance of the incubated mixture at $340 \mathrm{~nm}$ over $3 \mathrm{~min}$. The GPx activity was expressed as units/g sample.

Superoxide dismutase: SOD activity was measured using a modified version of a pyrogallol autoxidation method described by Marklund and Marklund (1974). First, $5 \mathrm{~g}$ of sample was homogenized with cold $\left(4^{\circ} \mathrm{C}\right)$ phosphate buffer (pH 7.0 at $25^{\circ} \mathrm{C}$ ) using a homogenizer at $13,500 \mathrm{rpm}$ for 30 $\mathrm{s}$. Then, centrifugation was performed at $1,800 \times g$ for $15 \mathrm{~min}$ at $2^{\circ} \mathrm{C}$ using a JA-20 rotor (Beckman Instruments, Inc., Palo Alto, CA, USA) in a J2-21 centrifuge (Beckman Instruments, Inc., USA). The supernatant was filtered through a Whatman filter paper No. 1. Then, $50 \mu \mathrm{L}$ of filtrate was transferred to a crystal cuvette (light path: $1 \mathrm{~cm}$ ) and mixed with $3.025 \mathrm{~mL}$ of $50 \mathrm{mM}$ Tris-cacodylate-DTPA buffer $\left(\mathrm{pH} 8.2 ; 25^{\circ} \mathrm{C}\right)$ and $50 \mu \mathrm{L}$ of $24.8 \mathrm{mM}$ pyrogallol. The optical density was recorded at $420 \mathrm{~nm}$ every $15 \mathrm{~s}$ for $2 \mathrm{~min}$. The SOD activity was expressed as units/g $(\mathrm{U} / \mathrm{g})$. One unit $(1 \mathrm{U})$ of SOD 
represents the amount of SOD that is needed to auto oxidize $50 \%$ of the pyrogallol in the meat at $25^{\circ} \mathrm{C}$ and a $\mathrm{pH}$ of 8.2 .

\section{Iron contents measurement}

Heme-iron: The Heme-iron content was determined according to the Hornsey method of total pigment (hematin) analysis with modification (Hornsey, 1956). First, $10 \mathrm{~g}$ of sample was weighed into the $50 \mathrm{~mL}$ centrifuge tubes and was homogenized with $40 \mathrm{~mL}$ of acetone, $9 \mathrm{~mL}$ of distilled water and $1 \mathrm{~mL}$ of $11.3 \% \mathrm{HCl}$ using a homogenizer at 13,500 rpm for $15 \mathrm{~s}$. The homogenates were incubated in dark conditions for $1 \mathrm{~h}$ before centrifugation at $3,200 \times g$ for 10 min using a $\mathrm{JA}-20$ rotor in a J2-21 centrifuge. The supernatant was filtered through a Whatman paper (GE Healthcare Life Sciences, Amersham, UK), and the absorbance was measured at $640 \mathrm{~nm}$ against a reagent blank using a spectrophotometer (UV-mini-1240, Shimadzu Corp., Kyoto, Japan). The absorbance was multiplied by a factor of 6,800 and then divided by the sample weight to give the concentration of the total pigment in the meat as $\mu \mathrm{g}$ hematin/g meat. The iron content was calculated with a factor of $0.0882 \mu \mathrm{g}$ iron $/ \mu \mathrm{g}$ hematin (Clark et al., 1997).

Non-heme (free) iron content: The amount of free iron in the meat was measured based on a modified version of the ferrozine method (Carter, 1971; Ahn et al., 1993). A $5 \mathrm{~g}$ sample was homogenized with $45 \mathrm{~mL}$ of citrate phosphate buffer ( $\mathrm{pH} 5.5$ ) at 13,500 rpm for $30 \mathrm{~s}$ using a homogenizer. The homogenate was centrifuged at $3,500 \times \mathrm{g}$ for $20 \mathrm{~min}$ using a JA-20 rotor and a J2-21 centrifuge. Next, $1 \mathrm{~mL}$ of the supernatant was mixed with $0.5 \mathrm{~mL}$ of freshly prepared $2 \%$ ascorbic acid in $0.2 \mathrm{~N} \mathrm{HCl}$ and incubated at room temperature for $5 \mathrm{~min}$. Then, the mixture was mixed thoroughly with $1.5 \mathrm{~mL}$ of $11.3 \%$ tri-chloroacetic acid followed by centrifugation at $10,000 \times g$ in an Eppendorf Micro 17R+ centrifuge (Hanil Science Industrial Co., Ltd., Incheon, Korea) for $10 \mathrm{~min}$. Last, $1 \mathrm{~mL}$ of supernatant was mixed with $0.4 \mathrm{~mL}$ of $10 \%$ ammonium acetate and $0.1 \mathrm{~mL}$ of ferroin indicator followed by $5 \mathrm{~min}$ incubation. The absorbance was read at $562 \mathrm{~nm}$ against a blank. The free iron value was expressed as $\mu \mathrm{g} / \mathrm{g}$ sample. The total iron was calculated by a summation of the heme iron and non-heme iron.

\section{Lipid oxidation}

Lipid oxidation of the raw and cooked meats was determined by measuring the thiobarbituric acid reactive substances (TBARS) value according to Sinnhuber and Yu (1977). A 0.5 g ground sample was mixed with 3 drops of an antioxidant solution (3\% BHA-54\% propylene glycol-3\% BHT-40\% Tween 20 ), $3 \mathrm{~mL}$ of a thiobarbituric acid solution (1\% 4,6-Dihydroxy-2-mercaptopyrimidine), and $17 \mathrm{~mL}$ of $25 \%$ trichloroacetic acid. The mixture was heated in a water bath at $100^{\circ} \mathrm{C}$ for $30 \mathrm{~min}$ followed by cooling for $30 \mathrm{~min}$. The mixture was then centrifuged at $2,400 \times g$ for $30 \mathrm{~min}$. The absorbance value of the supernatant was measured at $532 \mathrm{~nm}$ using a spectrophotometer (UV-mini-1240, Shimadzu, Japan). The results were calculated as $\mathrm{mg}$ malonaldehyde $/ \mathrm{kg}$ sample. Four measurements were performed on each sample.

\section{Statistical analysis}

Three animals per breed were used in this study; the breast and thigh meat from both the left and right sides were used as a separate sample in this study $(n=6)$. All data were expressed as the mean \pm standard error and were analyzed with a one-way analysis of variance procedure from SPSS 19.0 (SPSS Inc., Chicago, IL, USA) followed by Duncan's multiple range tests. The activity of antioxidant enzyme, iron content and TBARS values were significantly different among meat parts. The statistical significance was accepted at the $95 \%$ significance level $(\mathrm{p}<0.05)$.

\section{RESULTS AND DISCUSSION}

\section{Antioxidant enzyme activity}

The antioxidant enzyme activities, which included the activities of CAT, GPx, and SOD in raw and cooked breast and thigh meat are presented in Table 1 and 2, respectively. The CAT activity of raw thigh meat was higher than that of breast meat in the broiler, and the CAT activity of the thigh meat was higher than that of the breast meat of the Woorimatdak and Yeonsan ogye $(\mathrm{p}<0.05)$. Lee et al. (1996) reported a higher CAT activity from the thighs than from the breasts of turkey. Those data showed that the CAT activity of the meat, which are redder in all chicken breeds, was higher than breast, which is white. Muscle fibers can be categorized into two different metabolic types, oxidative (red) or glycolytic (white), based on their chemical composition and enzyme activities (Lawrie, 1979). Renerre et al. (1996) showed a result that oxidative muscle had higher antioxidant enzyme activities than glycolytic muscle. While these results support increased antioxidant enzyme expression in the highly-oxidative environments of living tissues, it does not substantiate the role for these enzymes in postmortem muscle tissues or meat (Bekhit et al., 2013). The breast meat of the Pekin duck had higher CAT activity than the thighs $(\mathrm{p}<0.05)$. Those findings were different from the results in chickens because both breast and thigh muscles of duck are categorized as dark meat. Compared to other species, CAT in poultry meat was lower than in both beef and pork muscle (Mei et al., 1994). Meanwhile, the CAT activity of cooked meat was not detected in this study. Mei et al. (1994) reported that the CAT was completely inactivated in pork and beef when cooked to $80^{\circ} \mathrm{C}$, just as it had been in ground turkey (Lee et al., 1996).

The Pekin duck had the highest GPx activities of raw meat among poultry breeds. Daun and Akesson (2004) noted 
Table 1. Antioxidant enzyme activity of raw and cooked breast meat from different breeds of poultry

\begin{tabular}{|c|c|c|c|c|c|c|}
\hline \multirow{2}{*}{ Poultry breeds } & \multicolumn{2}{|c|}{ CAT (units/g) } & \multicolumn{2}{|c|}{ GPx (units/g) } & \multicolumn{2}{|c|}{ SOD (units/g) } \\
\hline & Raw & Cooked $^{1}$ & Raw & Cooked & Raw & Cooked \\
\hline Broiler & $78.66 \pm 11.40^{y}$ & - & $0.39 \pm 0.10^{y}$ & $0.12 \pm 0.01^{z}$ & $30.58 \pm 1.20^{y}$ & $22.78 \pm 2.25^{y}$ \\
\hline White Leghorn & $58.99 \pm 12.80^{y}$ & - & $0.38 \pm 0.11^{\mathrm{y}}$ & $0.11 \pm 0.02^{z}$ & $56.47 \pm 2.98^{x y}$ & $30.22 \pm 2.32^{x y}$ \\
\hline Pekin duck & $126.27 \pm 22.30^{x}$ & - & $2.01 \pm 0.08^{x}$ & $0.28 \pm 0.12^{\mathrm{x}}$ & $75.86 \pm 2.25^{\mathrm{x}}$ & $45.15 \pm 1.74^{\mathrm{x}}$ \\
\hline Woorimatdak & $49.68 \pm 17.50^{z}$ & - & $0.45 \pm 0.10^{\mathrm{y}}$ & $0.16 \pm 0.01^{\mathrm{y}}$ & $84.71 \pm 3.86^{x}$ & $45.85 \pm 3.71^{x}$ \\
\hline Yeonsan ogye & $60.72 \pm 13.10^{y}$ & - & $0.33 \pm 0.20^{z}$ & $0.27 \pm 0.06^{x}$ & $31.76 \pm 1.88^{y}$ & $22.96 \pm 1.52^{y}$ \\
\hline Hyunin black & $62.10 \pm 13.30^{y}$ & - & $0.22 \pm 0.10^{\mathrm{z}}$ & $0.16 \pm 0.04^{y}$ & $63.52 \pm 2.42^{x y}$ & $35.68 \pm 4.11^{\mathrm{x}}$ \\
\hline
\end{tabular}

${ }^{1}$ Cooking inactivated catalase (CAT) and decreased the activity of glutathione peroxidase (GPx) and superoxide dismutase (SOD) significantly (p<0.05).

${ }^{x-z}$ Means in the same column followed by different letters in superscript are significantly different $(p<0.05)$

that duck meat is categorized as oxidative muscle (red muscle) which has more mitochondria and myoglobin than white muscle. In addition, oxidative muscle (red muscle) exhibits higher GPx activity than glycolytic muscle (white muscle) (DeVore et al., 1983). The GPx activity of the Pekin duck meat was higher than that for chicken meat, and it ranged from three to ten times higher than that of any chicken breed studied. Our results were lower compared to previous findings from Hoac et al. (2006) who reported that the GPx activity in duck meat was approximately ten times higher than the GPx activity in chicken meat. In the Pekin duck, the GPx activity in the thigh and breast meat was not significantly different, while the thigh meat had higher GPx activity than other meat parts in all the chicken breeds. Our results are in agreement with DeVore et al. (1983) and Lee et al. (1996) who reported that oxidative muscle had higher GPx activities than breast meat. In particular, the GPx activities in the Yeonsan ogye and Hyunin black meat were lower than in the Pekin duck, Woorimatdak and White Leghorn, but were similar to the broiler.

Heating significantly decreased GPx activity in all meat parts of all poultry breeds. It was different from CAT activity, which was inactivated by cooking. The GPx activity in cooked meat samples was still detected; however, it was lower than in raw meat. The decrease in the GPx activity after cooking varied from $18 \%$ to $86 \%$. The percentage of GPx activity reduction by cooking the breast meat of the Yeonsan ogye and Hyunin black was $18 \%$ and $27 \%$, respectively. Those values indicate that the GPx activities in the breast meat of the Yeonsan ogye and Hyunin black seemed to be more tolerant against high temperature. Lee et al. (1996) reported that GPx activity decreased up to $96 \%$ after cooking. A greater decrease in the GPx activity after cooking was found for meat with higher GPx activities in the raw state. Thigh meat of the Yeonsan ogye and Hyunin black, and the breast meat of the broiler and Woorimatdak exhibited the lowest GPx activities among cooked chicken meat samples used in this study $(\mathrm{p}<0.05)$.

The SOD activity in the raw meat samples varied among meat parts and chicken breeds. The breast meat of the White Leghorn, Woorimatdak and Hyunin black had higher activity than that of their thigh meat $(\mathrm{p}<0.05)$. The breast and thigh meat of Pekin duck were not different. The breast meat of Woorimatdak and Pekin duck had higher SOD activity than the others, while only the thigh meat of Pekin duck had the highest activity.

Cooking reduced the SOD activities and no differences were found for the SOD activities in cooked meat with respect to the meat parts for the broiler, White Leghorn and Pekin duck. In the Hyunin black, cooked breast meat had higher SOD activities than did the thigh meat, but in the Yeonsan ogye, the breast meat exhibited a lower SOD activity than did the thigh meat $(\mathrm{p}<0.05)$. This, however, endogenous SOD that released from mitochondria during cooking are not strongly associated with the development of lipid oxidation in cooked pork and beef (Mei et al., 1994).

\section{Iron content and lipid oxidation}

The iron content of breast and thigh meat are shown in Table 3 and 4, respectively. The thigh meat of the

Table 2. Antioxidant enzyme activity of raw and cooked thigh meat from different breeds of poultry

\begin{tabular}{|c|c|c|c|c|c|c|}
\hline \multirow{2}{*}{ Poultry breeds } & \multicolumn{2}{|c|}{ CAT (units/g) } & \multicolumn{2}{|c|}{ GPx (units/g) } & \multicolumn{2}{|c|}{ SOD (units/g) } \\
\hline & Raw & Cooked $^{1}$ & Raw & Cooked & Raw & Cooked \\
\hline Broiler & $95.22 \pm 13.40^{y}$ & - & $0.45 \pm 0.10^{\mathrm{z}}$ & $0.32 \pm 0.02^{\mathrm{y}}$ & $42.35 \pm 1.67^{y}$ & $24.88 \pm 3.60^{y}$ \\
\hline White Leghorn & $128.34 \pm 17.60^{x}$ & - & $0.60 \pm 0.10^{y}$ & $0.34 \pm 0.03^{y}$ & $45.88 \pm 1.47^{y}$ & $28.85 \pm 2.54^{y}$ \\
\hline Pekin duck & $65.49 \pm 17.80^{z}$ & - & $1.91 \pm 0.02^{\mathrm{x}}$ & $0.57 \pm 0.12^{\mathrm{x}}$ & $77.64 \pm 2.80^{\mathrm{x}}$ & $45.77 \pm 1.52^{\mathrm{x}}$ \\
\hline Woorimatdak & $111.78 \pm 12.40^{\mathrm{x}}$ & - & $0.59 \pm 0.03^{y}$ & $0.24 \pm 0.10^{\mathrm{y}}$ & $52.94 \pm 1.08^{y}$ & $38.32 \pm 3.89^{\mathrm{x}}$ \\
\hline Yeonsan ogye & $97.29 \pm 14.30^{y}$ & - & $0.36 \pm 0.10^{z}$ & $0.15 \pm 0.01^{\mathrm{z}}$ & $49.41 \pm 2.55^{y}$ & $27.74 \pm 2.85^{\mathrm{y}}$ \\
\hline Hyunin black & $83.22 \pm 14.60^{y}$ & - & $0.47 \pm 0.02^{z}$ & $0.11 \pm 0.05^{z}$ & $31.76 \pm 1.98^{z}$ & $20.52 \pm 2.16^{z}$ \\
\hline
\end{tabular}

\footnotetext{
${ }^{1}$ Cooking inactivated catalase (CAT) and decreased the activity of glutathione peroxidase (GPx) and superoxide dismutase (SOD) significantly (p<0.05).
}

${ }^{\mathrm{x}-\mathrm{z}}$ Means in the same column followed by different letters in superscript are significantly different $(\mathrm{p}<0.05)$. 
Woorimatdak, White Leghorn, Yeonsan ogye and Hyunin black breeds contained more iron than their breast meat. However, the breast meat of the Pekin duck contained more iron than the thigh meat. Lombardi-Boccia et al. (2002) reported that the oxidative meat contained more iron than the breast meat of the broiler and turkey. The presence of higher myoglobin and hemoglobin concentrations in oxidative meat is associated with this finding. Lombardi-Boccia et al. (2002) also reported that the heme iron contents markedly differed among the meat cuts; in chicken legs and wings, heme iron was higher than that of the breast meat and similar results were found for turkey meat. This report is in agreement with our findings, in which heme and non-heme iron content varied among meat parts of different chicken breeds and duck. No difference in the content of heme iron was found in the raw meat parts of Hyunin black. The thigh meat of Yeonsan ogye and Woorimatdak, however, had more heme iron than breast meat $(p<0.05)$, and the duck meat contained the highest amount of heme-iron than other breeds $(p<0.05)$. Raw Pekin duck meat contained the highest total iron, followed by the raw meat of the White Leghorn, Yeonsan ogye, Hyunin black, broiler, and Woorimatdak.

The cooked breast meat of the White Leghorn, Yeonsan ogye and Hyunin black contained lower heme iron content than the cooked thigh meat $(\mathrm{p}<0.05)$. This finding was in contrast with the results of the Pekin duck, in which the cooked breast meat had higher heme iron than the cooked thigh meat $(\mathrm{p}<0.05)$. The cooked thigh meat of the broiler and Woorimatdak contained higher heme iron than the breast meat of the same breeds $(\mathrm{p}<0.05)$. The non-heme iron data of the cooked meat showed that the thigh meat contained higher amounts than the breast meat in all poultry breeds excluding the broiler.

Min and Ahn (2005) mentioned that the release of iron from myoglobin or heme complex is known to play role in lipid oxidation. Table 5 and 6 presents the iron release percentages after cooking and TBARS values of the breast and thigh meat, respectively. The heme loss ranged from $3.30 \%$ to $14.80 \%$ for breast meat and $6.40 \%$ to $14.00 \%$ for thigh meat. These losses varied among meat parts and poultry breeds, in which the same meat part of each breeds showed different iron loss percentages. The percentage of iron released after cooking was found higher in both breast and thigh meat of Hyunin black. For breast meat, White Leghorn, Hyunin black and Yeonsan ogye lost their heme iron higher than the others, while similar trend also was found in the thigh meat of Pekin duck followed by Hyunin black. Lombardi-Boccia et al. (2002) showed contrasting results with our findings, in which the decrease in iron in the breast meat of the broiler and turkey was less than for the leg and wing meat following pan cooking; however, the different cooking methods may be responsible for the differences in iron loss in this comparison.

No differences in the TBARS values of raw meat were found among chicken breeds $(p<0.05)$. The raw meat of Pekin duck had exceptionally high TBARS values than all chicken breeds, in which the higher value was found in its breast meat instead of thigh meat. After cooked, the TBARS values of its breast and thigh meat were not different. For chicken breeds, the TBARS values varied among the meat parts of different breeds. The raw breast meat had the lowest TBARS values than the thigh of all chicken breeds. The

Table 3. Iron contents of raw and cooked breast meat of different breeds of poultry

\begin{tabular}{|c|c|c|c|c|c|c|}
\hline \multirow{2}{*}{ Poultry breeds } & \multicolumn{2}{|c|}{ Heme iron $(\mu \mathrm{g} / \mathrm{g})$} & \multicolumn{2}{|c|}{ Non-heme iron $(\mu \mathrm{g} / \mathrm{g})$} & \multicolumn{2}{|c|}{ Total iron $(\mu \mathrm{g} / \mathrm{g})$} \\
\hline & Raw & Cooked & Raw & Cooked & Raw & Cooked \\
\hline Broiler & $1.27 \pm 0.01^{\mathrm{y}}$ & $1.38 \pm 0.03^{y}$ & $0.37 \pm 0.03^{\mathrm{x}}$ & $0.48 \pm 0.01^{\mathrm{y}}$ & $1.64 \pm 0.05^{y}$ & $1.86 \pm 0.31^{\mathrm{y}}$ \\
\hline White Leghorn & $1.16 \pm 0.23^{\mathrm{y}}$ & $1.35 \pm 0.08^{y}$ & $0.26 \pm 0.10^{\mathrm{x}}$ & $0.67 \pm 0.09^{x}$ & $1.42 \pm 0.25^{\mathrm{y}}$ & $2.02 \pm 0.25^{\mathrm{y}}$ \\
\hline Pekin duck & $8.37 \pm 0.44^{\mathrm{x}}$ & $7.04 \pm 0.14^{\mathrm{x}}$ & $0.24 \pm 0.01^{\mathrm{x}}$ & $0.81 \pm 0.01^{\mathrm{x}}$ & $8.61 \pm 0.15^{\mathrm{x}}$ & $7.85 \pm 0.16^{\mathrm{x}}$ \\
\hline Woorimatdak & $0.99 \pm 0.03^{\mathrm{y}}$ & $1.64 \pm 0.02^{\mathrm{y}}$ & $0.18 \pm 0.01^{\mathrm{y}}$ & $0.44 \pm 0.03^{y}$ & $1.17 \pm 0.03^{\mathrm{y}}$ & $2.08 \pm 0.03^{\mathrm{y}}$ \\
\hline Yeonsan ogye & $1.42 \pm 0.28^{\mathrm{y}}$ & $1.65 \pm 0.28^{y}$ & $0.33 \pm 0.06^{\mathrm{x}}$ & $0.73 \pm 0.12^{\mathrm{x}}$ & $1.75 \pm 0.09^{y}$ & $2.38 \pm 0.18^{y}$ \\
\hline Hyunin black & $1.34 \pm 0.22^{\mathrm{y}}$ & $1.57 \pm 0.19^{y}$ & $0.31 \pm 0.01^{\mathrm{x}}$ & $0.75 \pm 0.08^{x}$ & $1.65 \pm 0.20^{y}$ & $2.32 \pm 0.29^{y}$ \\
\hline
\end{tabular}

${ }^{x-y}$ Means in the same column followed by different letters in superscript are significantly different $(\mathrm{p}<0.05)$.

Table 4. Iron contents of raw and cooked thigh meat of different breeds of poultry

\begin{tabular}{|c|c|c|c|c|c|c|}
\hline \multirow{2}{*}{ Poultry breeds } & \multicolumn{2}{|c|}{ Heme iron $(\mu \mathrm{g} / \mathrm{g})$} & \multicolumn{2}{|c|}{ Non-heme iron $(\mu \mathrm{g} / \mathrm{g})$} & \multicolumn{2}{|c|}{ Total iron $(\mu \mathrm{g} / \mathrm{g})$} \\
\hline & Raw & Cooked & Raw & Cooked & Raw & Cooked \\
\hline Broiler & $1.46 \pm 0.02^{y}$ & $2.23 \pm 0.24^{\mathrm{y}}$ & $0.24 \pm 0.01^{\mathrm{y}}$ & $0.62 \pm 0.01^{y}$ & $1.70 \pm 0.26^{\mathrm{y}}$ & $2.85 \pm 0.25^{\mathrm{y}}$ \\
\hline White Leghorn & $2.05 \pm 0.31^{\mathrm{x}}$ & $2.84 \pm 0.28^{\mathrm{y}}$ & $0.45 \pm 0.09^{\mathrm{x}}$ & $0.92 \pm 0.10^{x y}$ & $2.50 \pm 0.12^{\mathrm{x}}$ & $3.76 \pm 0.18^{x y}$ \\
\hline Pekin duck & $2.47 \pm 0.53^{x}$ & $4.22 \pm 0.15^{\mathrm{x}}$ & $0.23 \pm 0.03^{\mathrm{y}}$ & $1.23 \pm 0.03^{\mathrm{x}}$ & $2.70 \pm 0.17^{x}$ & $5.45 \pm 0.15^{\mathrm{x}}$ \\
\hline Woorimatdak & $1.23 \pm 0.02^{\mathrm{y}}$ & $3.74 \pm 0.09^{x}$ & $0.24 \pm 0.02^{\mathrm{y}}$ & $1.21 \pm 0.01^{\mathrm{x}}$ & $1.47 \pm 0.06^{\mathrm{y}}$ & $4.95 \pm 0.15^{\mathrm{x}}$ \\
\hline Yeonsan ogye & $2.04 \pm 0.30^{\mathrm{x}}$ & $2.44 \pm 0.58^{y}$ & $0.45 \pm 0.05^{\mathrm{x}}$ & $0.86 \pm 0.20^{x y}$ & $2.49 \pm 0.17^{\mathrm{x}}$ & $3.30 \pm 0.35^{\mathrm{xy}}$ \\
\hline Hyunin black & $1.60 \pm 0.34^{\mathrm{y}}$ & $2.04 \pm 0.29^{y}$ & $0.35 \pm 0.04^{\mathrm{x}}$ & $0.82 \pm 0.04^{x y}$ & $1.95 \pm 0.13^{\mathrm{xy}}$ & $2.86 \pm 0.28^{y}$ \\
\hline
\end{tabular}

\footnotetext{
${ }^{\mathrm{x}-\mathrm{y}}$ Means in the same column followed by different letters in superscript are significantly different $(\mathrm{p}<0.05)$
} 
Table 5. Percentage of iron release and TBARS value of raw and cooked breast meat of different breeds of poultry

\begin{tabular}{lccccc}
\hline \multirow{2}{*}{ Poultry breeds } & \multicolumn{2}{c}{ Heme iron (\%) } & \multirow{2}{*}{ Heme iron release (\%) } & \multicolumn{2}{c}{ TBARS (mg MA/kg) } \\
\cline { 2 - 3 } \cline { 5 - 6 } & Raw & Cooked & & Raw & $0.14 \pm 0.02^{\mathrm{y}}$ \\
Broiler & 77.4 & 74.1 & 3.2 & $0.13 \pm 0.01^{\mathrm{y}}$ & $0.76 \pm 0.07^{\mathrm{y}}$ \\
White Leghorn & 81.6 & 66.8 & 14.8 & $1.02 \pm 0.20^{\mathrm{x}}$ & $2.21 \pm 0.27^{\mathrm{x}}$ \\
Pekin duck & 97.2 & 89.6 & 7.5 & $0.27 \pm 0.02^{\mathrm{y}}$ & $0.58 \pm 0.12^{\mathrm{y}}$ \\
Woorimatdak & 84.6 & 78.8 & 5.7 & $0.12 \pm 0.02^{\mathrm{y}}$ & $0.78 \pm 0.08^{\mathrm{y}}$ \\
Yeonsan ogye & 81.1 & 69.3 & 11.8 & $0.13 \pm 0.01^{\mathrm{y}}$ & $0.95 \pm 0.10^{\mathrm{y}}$ \\
Hyunin black & 81.2 & 67.6 & 13.5 & &
\end{tabular}

TBARS, thiobarbituric acid reactive substances; MA, malonaldehyde.

${ }^{\mathrm{x}-\mathrm{y}}$ Means in the same column followed by different letters in superscript are significantly different $(\mathrm{p}<0.05)$.

Table 6. Percentage of iron release and TBARS value of raw and cooked thigh meat of different breeds of poultry

\begin{tabular}{|c|c|c|c|c|c|}
\hline \multirow{2}{*}{ Poultry breeds } & \multicolumn{2}{|c|}{ Heme iron $(\%)$} & \multirow{2}{*}{ Heme iron release $(\%)$} & \multicolumn{2}{|c|}{ TBARS (mg MA/kg) } \\
\hline & Raw & Cooked & & Raw & Cooked \\
\hline Broiler & 85.8 & 78.2 & 7.6 & $0.22 \pm 0.13^{\mathrm{y}}$ & $1.36 \pm 0.14^{y}$ \\
\hline White Leghorn & 82.0 & 75.5 & 6.4 & $0.32 \pm 0.07^{y}$ & $1.90 \pm 0.25^{\mathrm{xy}}$ \\
\hline Pekin duck & 91.4 & 77.4 & 14.0 & $0.56 \pm 0.06^{\mathrm{x}}$ & $2.51 \pm 0.17^{\mathrm{x}}$ \\
\hline Woorimatdak & 83.6 & 75.5 & 8.1 & $0.26 \pm 0.04^{y}$ & $0.84 \pm 0.12^{z}$ \\
\hline Yeonsan ogye & 81.9 & 73.9 & 8.0 & $0.25 \pm 0.06^{\mathrm{y}}$ & $0.86 \pm 0.07^{z}$ \\
\hline Hyunin black & 82.0 & 71.3 & 10.7 & $0.21 \pm 0.02^{\mathrm{y}}$ & $0.84 \pm 0.09^{\mathrm{z}}$ \\
\hline
\end{tabular}

TBARS, thiobarbituric acid reactive substances; MA, malonaldehyde.

${ }^{\mathrm{x}-\mathrm{z}}$ Means in the same column followed by different letters in superscript are significantly different $(\mathrm{p}<0.05)$.

cooked thigh meat of the broiler and White Leghorn had higher TBARS values than Korean native chicken $(\mathrm{p}<0.05)$, while no significant differences were found among Korean native chicken. Bekhit et al. (2013) reported higher oxidation levels in the oxidative-glycolytic and oxidative muscles (red muscle) compared with the glycolytic muscle (white muscle) due to higher mitochondria and myoglobin contents in the oxidative muscles.

\section{CONCLUSION}

The thigh meat of poultry breeds used in this study had higher CAT, GPx, and SOD activity and iron content than the breast meat. Among Korean native chickens, Woorimatdak showed higher antioxidant enzyme activity and lower released-iron percentage. However, the degree of lipid oxidation was similar. Further study is needed to observe the association between antioxidant enzyme activity, iron content and lipid oxidation in Korean native chicken grown with similar condition. Moreover, cooking inactivated CAT activity, decreased the activity of GPx and SOD, released iron from its heme-bound and promoted lipid oxidation.

\section{CONFLICT OF INTEREST}

We certify that there is no conflict of interest with any financial organization regarding the material discussed in the manuscript.

\section{ACKNOWLEDGMENTS}

This research was supported by the "Cooperative Research Program for Agriculture Science and Technology Development (PJ010533)" from the Rural Development Administration, Republic of Korea.

\section{REFERENCES}

Aebi, H. E. 1984. Catalase in vitro. Methods Enzymol. 105:121-126. Ahn, D. U., F. H. Wolf, and J. S. Sim. 1993. Three methods for determining nonheme iron in turkey meat. J. Food Sci. 58:288291.

Bekhit, A. E. D. A., D. L. Hopkins, F. T. Fahri, and E. N. Ponnampalam. 2013. Oxidative processes in muscle systems and fresh meat: Sources, markers, and remedies. Compr. Rev. Food Sci. Food Saf. 12:565-597.

Buettner, G. R. and B. A. Jurkiewicz. 1996. Catalytic metals, ascorbate and free radicals: combinations to avoid. Radiat. Res. 145:532-541.

Carter, P. 1971. Spectrophotometric determination of serum iron at the submicrogram level with a new reagent (ferrozine). Anal. Biochem. 40:450-458.

Chan, K. M. and E. A. Decker. 1994. Endogenous skeletal muscle antioxidants. Crit. Rev. Food Sci. Nutr. 34:403-426.

Chen, W., H. L. Zhu, Y. Shi, M. M. Zhao, H. Wang, and Y. Q. Zeng. 2012. Comparative analysis on antioxidative ability of muscle between laiwu pig and large white. Asian Australas. J. Anim. Sci. 25:1190-1196.

Clark, E. M., A. W. Mahoney, and C. E. Carpenter. 1997. Heme and total iron in ready-to-eat chicken. J. Agric. Food Chem. 45:124126. 
Daun, C. and B. Akesson. 2004. Comparison of glutathione peroxidase activity, and of total and soluble selenium content in two muscles from chicken, turkey, duck, ostrich and lamb. Food Chem. 85:295-303.

DeVore, V. R., G. R. Colnago, L. S. Jensen, and B. E. Greene. 1983. Thiobarbituric acid values and glutathione peroxidase activity inmeat from chickens fed a selenium-supplemented diet. J. Food Sci. 48:300-301.

Gatellier, P., Y. Mercier, and M. Renerre. 2004. Effect of diet finishing mode (pasture or mixed diet) on antioxidant status of Charolais bovine meat. Meat Sci. 67:385-394.

Halliwell, B. and J. M. C. Gutteridge. 1990. Role of free radicals and catalytic metal ions in human disease: An overview. Methods Enzymol. 186:1-85.

Hernandez, P., L. Zomeno, B. Arino, and A. Blasco. 2004. Antioxidant, lipolytic and proteolytic enzyme activities in pork meat from different genotypes. Meat Sci. 66:525-529.

Hoac, T., C. Daun, U. Trafikowska, J. Zackrisson, and B. Akesson. 2006. Influence of heat treatment on lipid oxidation and glutathione peroxidase activity in chicken and duck meat. Innov. Food Sci. Emerg. Technol. 7:88-93.

Hornsey, H. C. 1956. The colour of cooked cured pork. I. Estimation of the nitric oxide-haem pigments. J. Sci. Food Agric. 7:534540.

Lawrie, R. 1979. Meat Science. 3rd ed. Pergamon press, Oxford, UK.

Lee, S. K., L. Mei, and E. A. Decker. 1996. Lipid oxidation in cooked turkey as affected by added antioxidant enzymes. J. Food Sci. 61:726-728.

Lombardi-Boccia, G., B. Martinez-Dominguez, and A. Aguzzi. 2002. Optimization of heme iron analysis in raw and cooked red meat. Food Chem. 78:505-510.
Marklund, S. and G. Marklund. 1974. Involvement of the superoxide anion radical in the autooxidation of pyrogallol and a convenient assay for superoxide dismutase. Eur. J. Biochem. 47:469-474.

Mei, L., A. D. Crum, and E. A. Decker. 1994. Development of lipid oxidation and inactivation of antioxidant enzymes in cooked pork and beef. J. Food Lipids 1:273-283.

Mcmillin, K. W. 2008. Where is MAP going? A review and future potential of modified atmosphere packaging for meat. Meat Sci. 80:43-65.

Min, B. and D. U. Ahn. 2005. Mechanism of lipid peroxidation in meat and meat products-A review. Food Sci. Biotechnol. 14:152-163.

Min, B., K. C. Nam, J. Cordray, and D. U. Ahn. 2008. Endogenous factors affecting oxidative stability of beef loin, pork loin, and chicken breast and thigh meats. J. Food Sci. 73:439-446.

Pradhan, A. A., K. S. Rhee, and P. Hernandez. 2000. Stability of catalase and its potential role in lipid oxidation in meat. Meat Sci. 54:385-390.

Renerre, M., F. Dumont, and P. Gatellier. 1996. Antioxidative enzyme activities in relation to oxidation of lipid and myoglobin. Meat Sci. 43:111-121.

Schricker, B. R., D. D. Miller, and J. R. Stouffer. 1982. Measurement and content of nonheme and total iron in muscle. J. Food Sci. 47:740-743.

Sinnhuber, R. O. and T. C. Yu. 1977. The 2-thiobarbituric acid reaction, an objective measure of the oxidative deterioration occurring in fats and oil. J. Japan Oil Chem. Soc. 26:259-267.

Terevinto, A., A. Ramos, G. Castroman, M. C. Cabrera, and A. Saadoun. 2010. Oxidative status, in vitro iron-induced lipid oxidation and superoxide dismutase, catalase and glutathione peroxidase activities in rhea meat. Meat Sci. 84:706-710. 